\title{
O Trabalho da Escrita
}

\section{ZENIR CAMPOS REIS*}

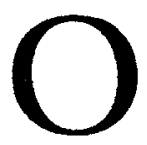

entendimento da formaçáo do escritor Graciliano Ramos exige o exame de variedade razoável de escritos, que convém recensear para, em seguida, propor critério de agrupamento.

Essa formaçáo exibe-se no conjunto de textos hoje conhecidos, começando em 1910 e vindo até 1930, com Caetés. São cartas, uma entrevista, crônicas, relatórios e, finalmente, o romance Caetés, sabe-se, foi redigido em 1926 e revisto, para publicação, em 1930, mas apenas três anos depois editado.

É indispensável considerar também o livro de memórias, Infancia, nesse contexto: ele é o que se poderia chamar de "formação reconstruída". O escritor adulto relata experiências que interessam à história de seu aprendizado.

A rigor, o livro ultrapassa bastante o momento de formaçáo, no sentido aqui considerado. Narrando seu contato com as palavras e com o mundo dos adultos, com a escrita e com seus vários usos, a obra projeta-se sobre a produção intelectual de Graciliano de modo mais amplo, como consciência reflexa, que cabe ainda avaliar. No momento, restrinjo-me a aspectos particulares, selecionados com o objetivo de evidenciar alguns procedimento de sua escrita, no período considerado.

A meu ver, pode-se pensar dois blocos de escritos, para efeito de exposição: um primeiro, objeto deste trabalho, que recolheria os elementos que se cristalizaram nas crônicas, até 1921, os "traços a esmo"; outro, englobando escritos prévios a Caetés, e o próprio romance, a objetivação mais orgânica desse momento de aprendizado.

Acerca do primeiro momento, quero destacar dois processos: a passagem da atividade fruidora para a atividade produtora de textos, e a

\footnotetext{
* Zenir Campos Reis é professor do Departamento de Letras Clássicas e Vernáculas da Faculdade de Filosofia, Lctras e Ciências Humanas da USP
} 
prática do discurso irônico - que me parece traço permanente de sua produção.

\section{II}

Foi para eliminar possível pressuposição de antítese entre passividade (fruição) e atividade (produção), que insisti em tratá-las ambas como atividades, apenas de qualidade diferente. Talvez se possa pensar que a diferença essencial consista em que, num caso, a atençăo se volte para a substância da narrativa (especificando esse tipo de texto) e, no outro, para a forma da narrativa. (Aqui, adoto a distinção proposta por C. $S$. Lewis, em $L$ 'expérience de critique littéraire, indicado na bibliografia final).

Extraio de Infancia um fragmento que pode ilustrar o que me parece uma situação de passagem de uma a outra atitude:

" Padre Pimentel era uma santa criatura e insinuou-me alguns conhecimentos, os primeiros que aceitei com prazer. Narrou-me a viagem de Abraáo, a vida nas tendas, a chegada à palestina. Usava linguagem simples, comparaçóes que atualizavam os acontecimentos. Não hesitei, ouvindo a mudança de homens e gado, com certeza tangidos pela seca, em situar a Caldéia no interior de Pernambuco. E Canaã, terra de leite e mel, aproximava-se dos engenhos e da cana de açúcar. Mantive essa localização arbitrária, útil à verossímilhança do enredo, espalhei seixos, mandacarus e xiquexiques no deserto Sírio, e isso não desapareceu inteiramente quando os mapas vieram". ("Um intervalo", p. 186).

A segunda frase sumária a substância da nararativa de Padre Pimentel: a viagem, a vida, a chegada: viagem de Abraão, vida nas tendas, chegada à Palestina.

$\mathrm{Na}$ frase seguinte, a forma: linguagem simples, comparaçóes atualizadoras.

Alain assinala que "Não há profunda diferença entre comparação e descriçáo; uma e outra fazem penetrar na expressão o mundo exterior; pois é sempre necessário que a necessidade exterior nos sustente os pensamentos". ("La comparaison, soutien des pensées", em - Prélimi. naires à l'estétique. S.l., Gallimard (c.1951), p.198).

O Padre quis ensinar a História Sagrada, mas ensinou mais: ensinou um procedimento do realismo literário, a comparação/descrição, e estimulou o exercício do menino: o nomadismo semita ancora-se no movimento migratório do nordestino pobre, a Caldéia enraíza-se no interior pernambucano, o leite e o mel de Canaá jorram dos engenhos e 
da cana de açúcar. A concretizaçáo prossegue no exercício de espalhar seixos, mandacarus e xiquexiques no deserto Sírio.

Chamo a atençằo para a escolha do verbo: "espalhei". Poderíamos esperar, em vez dele, "imaginei" . A energia do termo está na sua objetivação quase palpável, que diz uma atividade lúdica, de menino, espalhar pedrinhas, mas se entronca também com outra atividade, qualitativamente diversa, o trabalho.

Relembro a bela analogia que Graciliano estabelece entre a atividade artesanal de trançar urupemas do avô paterno e a de trançar palavras do neto escritor. Texto e tecido, aliás, sáo a mesma palavra.

Vale, talvez, comentar o trecho: refere-se àquele avô, "figura gemente e mesquinha, de ordinário ocupada, apesar da moléstiam em fabricar miudezas".

"Tinha habilidade notável e paciência. Paciência? Acho agora que náo é paciência. É uma obstinação concentrada, um longo sossego que os fatos exteriores náo perturbam. Os sentidos esmorecem, o corpo se imobiliza e curva, toda a vida se fixa em alguns pontos - no olho que brilha e se apaga, na máo que solta o cigarro e continua a tarefa, nos beiços que murmuram palavras imperceptíveis e descontentes. Sentimos desânimo ou irritação, mas isso apenas se revela pela tremura dos dedos, pelas rugas que se cavam. Na aparência estamos tranquiilos. Se nos falarem, nada ouviremos ou ignoraremos o sentido do que nos dizem. E como há frequientes suspensóes no trabalho, com certeza imaginarão que temos preguiça. Desejamos realmente abandoná-lo. Contudo gastamos uma eternidade no arranjo de ninharias, que se combinam, resultam na obra tormentosa e falha. Meu avô..." ("Manhä", Infancia, p. 21).

Com dificuldade reprimi o desejo de marcar essa transcrição com seus sinais de leitura: grifar o agora, que divide a impressão infantil de "paciência", da interpretação adulta de "obstinação"; de assinalar as partes sem dono daquele corpo: olhos, mãos e beiços; de instalar um semáforo no sóbrio cruzamento das duas pessoas verbais, - eu e ele implícito em "sentimos" e nas outras formas verbais pluralizadas.

"Meu avô nunca aprendera nenhum ofício. Conhecia, porém, diversos, e a carência de mestre não lhe trouxe desvantagem. Suou na composição das urupemas. Se resolvesse desmanchar uma, estudaria facilmente a fibra, $o$ aro, o tecido. Julgava isto um plágio. Trabalhador caprichoso e honesto, procurou os seus caminhos e executou urupemas fortes, seguras. Provavelmente não gostavam delas: prefeririam vê-las tradicionais e corriqueiras, enfeitadas e frágeis. $O$ Autor, insensível à crítica, perseverou nas urupemas rijas e sóbrias, não porque as estimasse, 


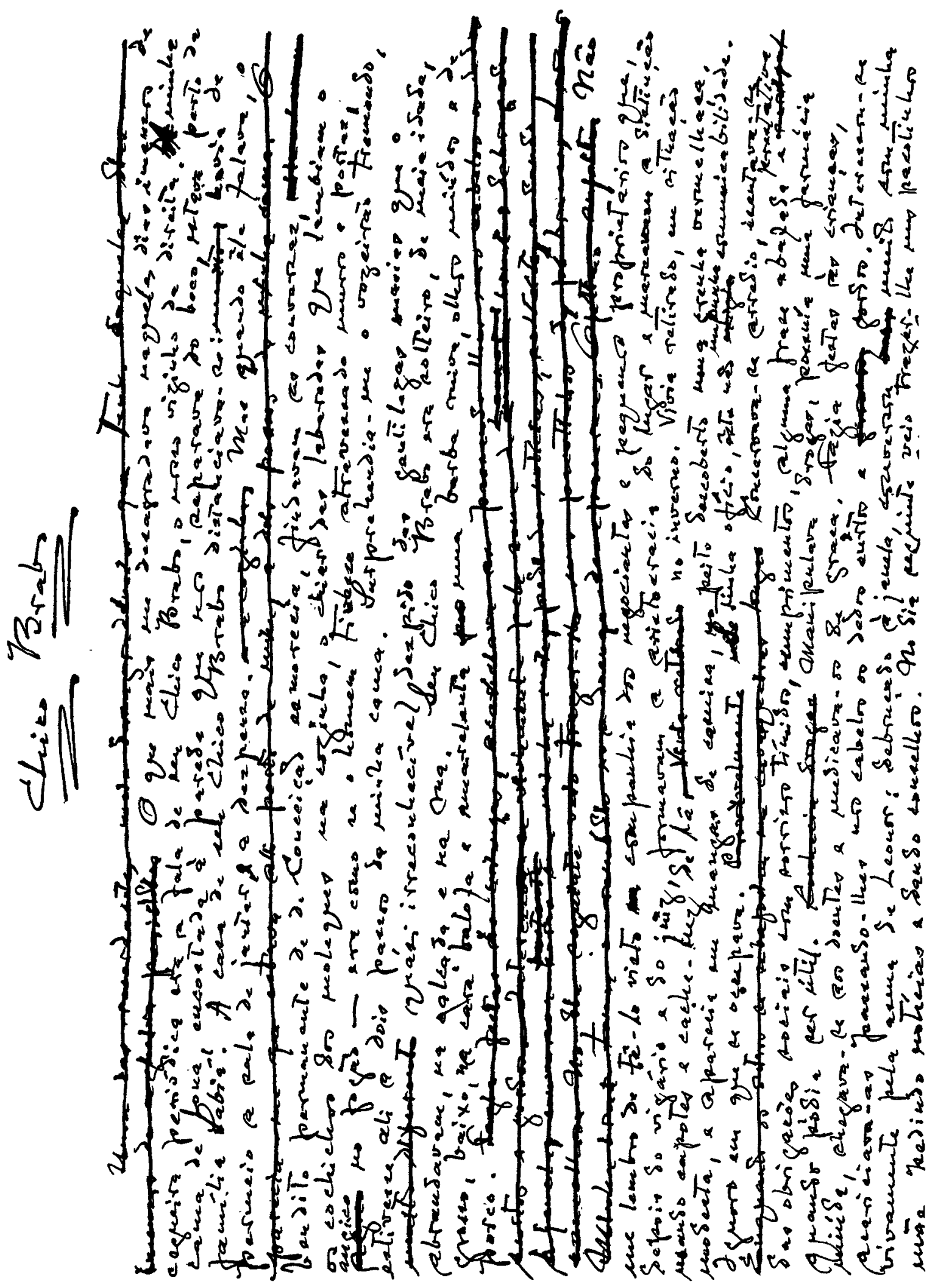

Manuscrito do captulo " Chico Brabo , de Infância, datado de 3 de agosto de 1943. Versäo diferente da publicada. Cortesia Arquino Graciliano Ramos, Strie Originais, Instituto de Estudos Brasileiros. 
mas porque eram o meio de expressão que lhe parecia mais razoável". (sequiência do trecho cit., p. 21-22).

Aqui há mais que uma poética: julgo ver aí o embrião de uma ética da produção artística e artesanal, fundada no trabalho. Semelhantemente, encontro em Alain: "reconheço-me escultor e proletário" ("Le potier", op.cit., p.157); e também "Bach é operário" ("L'artiste et le métier", op. cit., p. 215).

\section{III}

Foi também uma experiência infantil que abriu os olhos de Graciliano para o solo movediço sobre o qual se movem as palavras. Suas mestras foram as filhas de seu Nuno, devoto proprietário de loja de fazendas e padaria, em Viçosa:

"Essas moças tinham o vezo de afirmar o contrário do que desejavam. Notei a singularidade quando principiaram a elogiar o meu paletó cor de macaco. Examinavam-no sérias, achavam o pano e os aviamentos de qualidade superior, o feitio admirável. Envaideci-me: nunca havia reparado em tais vantagens. Mas os gabos se prolongaram, trou- 
xeram-me desconfiança. Percebi afinal que elas zombavam, e não me susceptibilizei. Longe disso: julguei curiosa aquela maneira de falar pelo avesso, diferente das grosserias a que me habituara. Em geral me diziam com franqueza que a roupa náo me assentava no corpo, sobrava nos sovacos. Os defeitos eram evidentes, e eu considerava estupidez virem indicá-los. Dissimulavam-se agora num jogo de palavras que encerrava malícia e bondade. Essa mistura de sentimentos incompativeis assombravam-me - e pela primeira vez ri de mim mesmo". ("Um intervalo", cit., p. 187-188).

Temos aqui interessante caracterizaçáo do recurso da ironia: como procedimento retórico e como mecanismo psicológico, além de instrumento potenciado de crítica. É claro que isso não dá conta de toda a multiformidade da ironia, hoje objeto de pesquisas especializadas ( $v$., na bibliografia, a revista Poétique), mas é suficiente para o início de uma discussáo sobre a incidência desse recurso na prosa de Graciliano.

O "falar pelo avesso" é, de fato, o modo mais comum da ironia e a repetiçáo, uma das marcas lingüísticas mais evidentes da intençáo irônica de um discurso.

Um dos momentos da descodificaçăo da ironia consiste em apreender o lado direito desse avesso. A ironia, de resto, opera com relativa transparência: no caso citado, a repetiçăo foi o indício verbal da intenção irônica. Mas, como lembra Beda Alleman, "A ironia literária é tanto mais irônica quanto sabe renunciar mais completamente aos sinais da ironia, sem lhe abandonar a transparência". (De l'ironie en tant que principe littéraire. Pottique, p. 390).

O risco da ironia é passar despercebida, e o discurso irônico ser tomado literalmente. $O$ próprio Graciliano tem sido vítima de malentendidos... Dizia-se que "para quem sabe ler um pingo de tinta no papel é letra" ou que "para bom entendedor..."

O recurso ao contexto é a melhor técnica de interpretaçăo: contexto restrito - totalidade do texto em foco - ou contexto amplo - conjunto de textos, conjunto da obra.

A ironia, de fato, faz conviver possibilidades de compreensáo e de interpretação contraditórias, no mesmo ato lingüístico, mas alimenta a esperança de que o leitor náo se equivoque. Em casos-limite, $o$ ironista pode estar esperando que o leitor conclua a partir da absoluta incongruência entre o sentido literal de seu texto e o testemunho de seu comportamento humano. A evidência lhe parece tal que o leitor não pode deixar de concluir que uma determinada afirmaçáo năo pode ser tomada literalmente, provindo de quem provém. 
O perigo da má interpretação não vem só: acompanha-o o de atualizar o pensante de um eventual inimigo. Alain diz: "A ironia é um jogo onde se perde sempre". E exemplifica: "Célimène ocupa o tempo em que o vaidoso, o tolo, o impertinente estão ausentes para fazê-los aparecer em seus discursos. Negando-os, ela os afirma; fá-los existir duas vezes". ("Conversations", em Propos, I, p. 462).

\section{IV}

Essa construção teórica que esbocei pode render alguma compreensáo e problematizaçáo das duas primeiras séries de crônicas, inclusas em Linbas tortas.

Para Graciliano Ramos, ali, ler é claramente eleger, termos que a memória da língua aproxima. Não é também casual que a linguagem do leitor se assemelhe tanto à do amoroso, como na crônica dedicada a Eça de Queirós, em 1915:

"Ele não é somente o escritor mais querido dos dois países, é uma individualidade à parte, adorada, idolatrada. Temos para com ele uma admiraçáo que chega às raias do fanatismo. (...) ele será sempre o grande Eça, o Eça que nos encanta, incomparável, deliciosamente espirituoso. (...)

"Confesso ingenuamente que às vezes cheguei a perguntar a mim mesmo se não haveria em Lisboa, junto ao grupo que representava a "Verdade" vclada pelo "manto diáfano da fantasia", algum templo de mármore onde sacerdotes inteligentes oficiassem, prestando culto à memória do grande ímpio. Supunha que lá aquele monstro de ironia tivesse mais ou menos as proporçóes de um dos antigos reformadores religiosos que a humanidade venera". (Linbas tortas, p. 15-17).

Em 1928, o autor dessas linhas não encontrou nada mais enérgico nem mais expressivo para declarar seu amor: "Achas extraordinário que me ajoelhe a teus pés e te adore? Por que não me ajoelharia, se não tenho deuses e o sentimento de religiosidade de que sou capaz se concentra em ti?" (Cartas, p. 93).

Tanto é verdadeiro que "o homem é um deus para o homem"... No fundo, o objetivo do amador/alquimista é transformar o dois em um: "Transforma-se o amador na coisa amada". O resultado, porém, é uma nova síntese, feita também de negociacóes: o um não poderá nunca ser igual a dois.

É assim que entendo o encontro entre Graciliano Ramos e Eça, 
primeiro momento da formação do romancista brasileiro: encontro desejado, afinidade eletiva, segunda natureza que se autonomiza.

"Manuel Tavares assassinou um homem". Fica-se na incerteza sobre se foi Manuel Tavares o assassino ou assassinado. Sendo "assassinar" um verbo transitivo, tanto the pode servir de agente Manuel Tavares como "um homem". Em casos assim ambíguos, a colocação das palavras em nada influi quanto ao sentido delas. Ninguém nos pode afirmar se o período está em ordem direta ou em ordem inversa. Dizem que "Manuel Tavares" é o sujeito. Por que? Porque está preso? É absurdo. Não há em gramática nenhuma regra que nos autorize a dizer que o agente da má açáo é o que está na cadeia. Alteremos a ordem em que aquilo está, invertamos os termos da oração e teremos: "Um homem assassinou Manuel Tavares". A dúvida permanece. (Linhas tortas, p. 64-65).

Na pele de um juiz de fato, o cronista J. Calixto arremeda a falácia jurídica, que parece aqui zombar do bom senso. Pirandello ensina que "quem quer imitar a outrem tem de tomar seus traços mais destacados e insistir sobre eles" ("O humor", em Ensayos, p. 85). É um dos procedimentos do discurso irônico que ele provoca vem acompanhado da consciência de que a distância entre a fraude $\mathrm{e}$ a justiça pode não ser tão grande.

Isso é transparente. Menos transparente é o lado direito desse complicado jogo com os avessos: o discurso irônico pode sempre parecer complacente, mistura de "malícia e bondade", e assim o entendeu o leitor a que se responde, crônicas adiante. O leitor considerou-o "um documento imoral, capaz de trazer aos (...) cidadãos (...) um poderoso estímulo para se tornarem criminosos" (p. 77). Descontada a bestice moralista e outras que o cronista vai expondo ao ridículo, deve-se recear os efeitos da ironia que já Goethe apontou: "a longo prazo provoca o tédio dos homens esclarecidos, induz os fracos ao erro e, claro, conforta a grande classe intermediária, que sem motivos particulares para se pôr a salvo, pode julgar-se mais astuciosa que os outros" (apud ALLEMAN, cit, p. 386).

Examinemos agora um trecho de outra crônica (abr., 1921):

"Sabem os senhores ereges, que nunca fizeram penitência, a terrível coisa que é o jejum? Năo sabem. 
Pois eu digo. Levanta-se uma alma piedosa pela manhā, executa uma razoável quantidade de rezas, limpa os dentes, se tem esse costume, lava os olhos, senta-se à mesa e ingere uma certa porçáo de café, uma porçāo regular, pois isto de jejuar sem café esté banido, que ninguém é de ferro.

Às onze horas o penitente almoça um quilo de bacalhau, três pratos de arroz com feijão, uma travessa de folhas de bredo, algumas dezenas de bananas, mangas e outras frutas, café e... só. Alguns engolem também uma traíra do açude, mas isso não é obrigatório. Mesmo sem ela, fica-se bem jejuado.

Devora-se tudo com fé. Para que a cerimônia tenha valor é preciso haver uma firme intenção no ânimo de quem a pratica.

Depois do almoço, que finda às duas horas da tarde, dorme-se. Enquanto se ronca, proibição completa de mastigar qualquer coisa.

Às sete da noite, acorda-se e ceia-se. A ceia, em qualidade e quantidade, é igual ao almoço. Come-se tudo, menos os pratos, que são de louça e necessários se tornam para o serviço do dia seguinte. Faz-se o sacrifício de não jantar, por dois motivos: primeiro porque o jantar quebra o jejum; segundo porque seria difícil encontrar onde colocá-lo". (Linhas tortas, p. 74).

Isto é o que Pirandello caracterizaria como "exagerar o exagero", ou "forçar os meios expressivos" (op. cit, p. 97-98). O ironista nesse exemplo casa o riso e a reflexão sobre a singular psicologia do hipócrita: não crê nos preceitos que exteriormente proclama, mas quer enganar a opiniāo chamando a gula de jejum.

A partir desses dois exemplos podemos obter um resultado interessante: quem é que chama a fraude de justiça ou a gula de jejum? Náo exatamente o ironista, cujo comportamento é transparente, mas sim o mentiroso, que apenas em grau se distingue do ideólogo. Existe, pois, uma modalidade de "falar pelo avesso" que é a ideologia, justificação da (des)ordem social vigente ou dominante. $O$ ironista, neste caso, encontra-se no avesso do avesso.

Com ou sem ironia, foi sempre esse o sentido do discurso contraideológico de todos os tempos. Lemos, por exemplo, em Isaias, 5, 20:

"Ai daqueles que ao mal chamam bem e ao bem, mal, que mudam as trevas em luz e a luz em trevas, que tornam doce o que é amargo, e amargo o que é doce!"

Da mesma natureza o discurso do velho do Restelo, nos Lustadas. Com acento irônico, temos as anti-utopias de George Orwell, 1984, e $A$ revolução dos bichos, denúncia dos totalitarismos contemporâneos. 


\section{Bibliografia}

ALAIN Propos. Gallimard, (1956) (Bibliothque de la Pléiade). V.1.S.1.p.

Preliminares a l'esthtique. S.1.p., Gallimard, (1951).

LEWIS, C. S. Exptrience de critique litttraire. (Paris): Gallimard, 1965).

PIRANDELLO, Luigi. Ensayos. Madrid: Guadarrama, 1968.

Potrique n.36 (Ironie). Paris: Seuil, nov. 1978.

RAMOS, Graciliano Linbas tortas. São Paulo: Martins, 1962. Infintia. Rio de Janeiro: J. Olympio, 1953. Cartas. Rio de Janeiro: Record, 1980. 